\begin{tabular}{|lllllllll|}
\hline J & O & UI & R & N & A & L & O & F \\
\hline
\end{tabular}

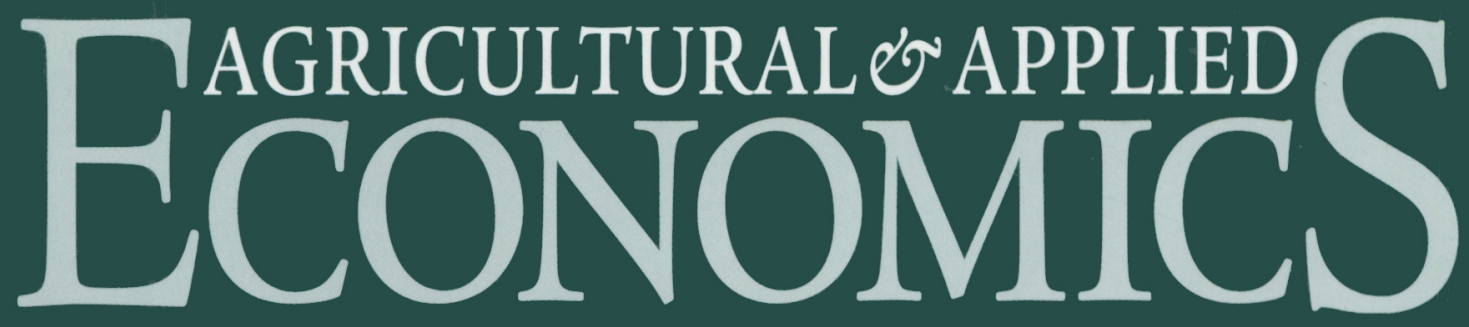

\title{
VOLLIME 39
}

\section{April 2007}

NUIMBER 1

\section{Articles}

Incentives for Quality / Corinne Alexander, Rachael E. Goodhue, and Gordon C. Rausser

Organic Food Shoppers / Lydia Zepeda and Jinghan Li

Hedonic Retail Prices / Joseph L. Parcell and T.C. Schroeder

South Korean Meat Demand / Shida Rastegari Henneberry and Seong-huyk Hwang

Farm Animal Welfare / Fredrik Carlsson, Peter Frykblom, and Carl Johan Lagerkvist

Forecast Rationality / Dwight R. Sanders and Mark R. Manfredo

Factor Price Disparity and Retained Ownership / Brad J. White, John D. Anderson, W. Blair McKinley, and Jane Parish

Economic Impacts of Biomass Feedstocks in Coal Utilities / Burton C. English, Kim Jensen, Jamey Menard, Marie E. Walsh, Craig Brandt, Jim Van Dyke, and Stanton Hadley

Trade Creation and Trade Diversion / Dwi Susanto, C. Parr Rosson, III, and Flynn J. Adcock

Decoupling U.S. Cotton Subsidies / Andrew Schmitz, Frederick Rossi, and Troy G. Schmitz

Working Farm CRP Participation / Dayton M. Lambert, Patrick Sullivan, and Roger Claassen

Refuge Requirements / Michael J. Livingston, Nicholas P. Storer, John W. Van Duyn, and George G. Kennedy

Allocating Dairy Advertising Expenditures / Todd M. Schmit and Harry M. Kaiser

Determinants of Return on Equity / Scott Boyd, Michael Boland, Kevin Dhuyvetter, and David Barton

Schools and Residential Property Values / Kwame Owusu-Edusei, Jr., Molly Espey, and Huiyan Lin 


\title{
EDITORIAL STAFF
}

\author{
Editor \\ Henry Kinnucan \\ Auburn University \\ Associate Editors \\ Dragan Miljkovic \\ North Dakota State University \\ Øystein Myrland \\ University of Tromsø, Norway
}

Editorial Council

\author{
Darrell J. Bosch \\ Virginia Tech \\ David L. Debertin \\ University of Kentucky \\ Mark Denbaly \\ Economist, USDA, ERS \\ Kevin C. Dhuyvetter \\ Kansas State University \\ Shenggen Fan \\ International Food Policy \\ Research Institute \\ Diane Hite \\ Auburn University \\ Michael M. Hudson \\ Mississippi State University \\ Scott H. Irwin \\ University of Illinois
}

\author{
P. Lynn Kennedy \\ Louisiana State University \\ Carl Johan Lagerkvist \\ Swedish University \\ of Agricultural Science \\ Andrew M. McKenzie \\ University of Arkansas \\ Daniel V. Rainey \\ University of Arkansas \\ Daryll E. Ray \\ University of Tennessee \\ Cathy A. Roheim \\ University of Rhode Island \\ Loren W. Tauer \\ Cornell University
}

\section{EDITORIAL POLICY}

The Journal of Agricultural and Applied Economics (JAAE) provides a forum for creative and scholarly work in agricultural economics and related areas. Contributions on methodology and applications in business, extension, research, and teaching phases of agricultural and applied economics are equally encouraged. Submitted manuscripts are subject to peer review for publication consideration. Submission of critiques or comments on JAAE articles are welcomed.

\section{EDITORIAL COMMUNICATIONS}

The editorship of the $J A A E$ will change with Volume 37. Please send all manuscript submissions and editorial correspondence for manuscripts submitted after June 30, 2004 to Henry W. Kinnucan, Editor, JAAE, Department of Agricultural Economics and Rural Sociology, 213 Comer Hall, Simmons Drive, Auburn University, Auburn, AL 36849-5401. Phone: (334) 844-5614; Fax: (334) 844-5639; Email: JAAE@auburn.edu.

The Journal of Agricultural and Applied Economics (ISSN 1074-0708) is published in April, August, and December by the Southern Agricultural Economics Association (SAEA). Visit our worldwide web site at http://www.agecon.uga.edu/ jaae/jaae.htm.

Copyright (C) 2007 by the Southern Agricultural Economics Association. Any article or other material published in the $J A A E$ may not be resubmitted for publication or republished elsewhere in full or in part without the written permission of the editor. 


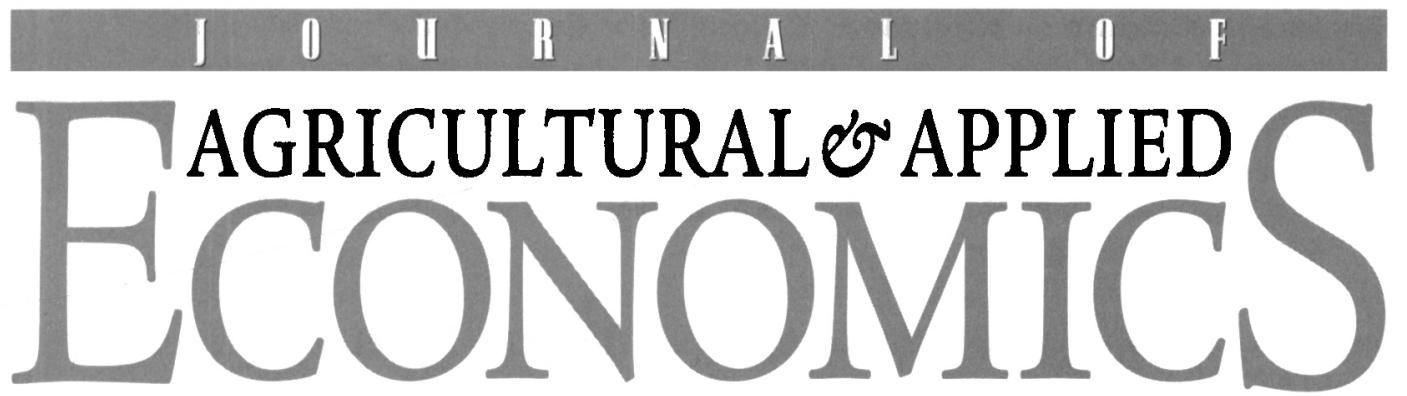

VOLLIME 39

APHIL 2007

NIMBER 1

\section{Articles}

Do Incentives for Quality Matter? / Corinne Alexander, Rachael E. Goodhue, and Gordon C. Rausser .......................................... 1

Characteristics of Organic Food Shoppers / Lydia Zepeda and Jinghan Li . . . . . . . 17

Hedonic Retail Beef and Pork Product Prices / Joseph L. Parcell and T.C. Schroeder......

Meat Demand in South Korea: An Application of the Restricted Source-Differentiated Almost Ideal Demand System Model / Shida Rastegari Henneberry and Seong-huyk

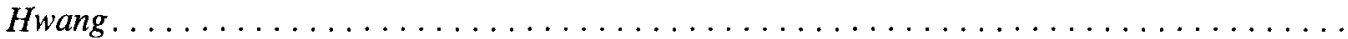

Farm Animal Welfare-Testing for Market Failure / Fredrik Carlsson, Peter Frykblom, and Carl Johan Lagerkvist . . . . . . . . . . . . . . . . . . . . . . . . . . . .

Rationality of U.S. Department of Agriculture Livestock Price Forecasts: A

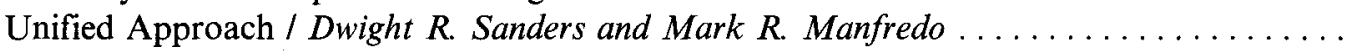

Factor Price Disparity and Retained Ownership of Feeder Cattle: An Application of Feedlot and Carcass Performance Data to Farm-Level Decision Making / Brad J. White, John D.

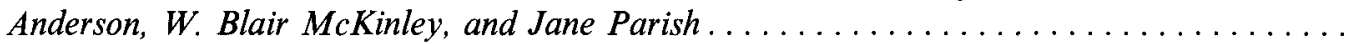

Economic Impacts of Carbon Taxes and Biomass Feedstock Usage in Southeastern United States Coal Utilities / Burton C. English, Kim Jensen, Jamey Menard, Marie E. Walsh, Craig Brandt, Jim Van Dyke, and Stanton Hadley. .

Trade Creation and Trade Diversion in the North American Free Trade Agreement: The Case of the Agricultural Sector / Dwi Susanto, C. Parr Rosson, III, and Flynn J. Adcock.....

U.S. Cotton Subsidies: Drawing a Fine Line on the Degree of Decoupling / Andrew Schmitz, Frederick Rossi, and Troy G. Schmitz............................

Working Farm Participation and Acreage Enrollment in the Conservation Reserve Program / Dayton M. Lambert, Patrick Sullivan, and Roger Claassen ...................

Do Refuge Requirements for Biotechnology Crops Promote Economic Efficiency? Some Evidence for Bt Cotton / Michael J. Livingston, Nicholas P. Storer, John W. Van Duyn, and

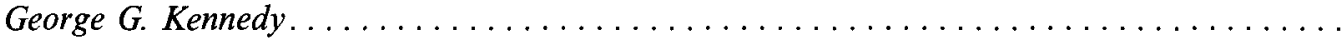

Optimal Seasonal Allocation of Generic Dairy Advertising Expenditures / Todd M. Schmit and Harry M. Kaiser. 
Determinants of Return on Equity in U.S. Local Farm Supply and Grain Marketing

Cooperatives / Scott Boyd, Michael Boland, Kevin Dhuyvetter, and David Barton . . . . . . 201

Does Close Count? School Proximity, School Quality, and Residential Property Values /

Kwame Owusu-Edusei, Jr., Molly Espey, and Huiyan Lin................... 211 